\title{
Artificial Solid Electrolyte Interphase Formation on Si Nanoparticles through Radiolysis: Importance of the Presence of an Additive
}

Chandra S. Bongu, ${ }^{a}$ Suzy Surblé, ${ }^{a}$ John P. Alper, ${ }^{a}$ Adrien Boulineau, ${ }^{b}$ Jean-Frédéric Martin, ${ }^{c}$ Alexandre Demarque, ${ }^{d}$ Pierre-Eugène Coulon, ${ }^{e}$ Michel Rosso, ${ }^{f}$ François Ozanam, ${ }^{f}$ Sylvain Franger, ${ }^{g}$ Nathalie Herlin-Boime ${ }^{a}$ and Sophie Le Caër ${ }^{a^{*}}$

${ }^{a}$ NIMBE, UMR 3685 CEA, CNRS, Université Paris-Saclay, CEA Saclay F-91191 Gif-surYvette Cedex, France. Université Paris Sud / Université Paris-Saclay F-91405 Orsay Cedex, France.

${ }^{b}$ CEA, LITEN, F-38054 Grenoble Cedex 9, France.

${ }^{c}$ CEA, LITEN, DEHT, STB, LM F-38054 Grenoble Cedex 9, France.

${ }^{d}$ Laboratoire de Chimie-Physique/ELYSE, UMR 8000 CNRS/UPS Université Paris Sud F-91405 Orsay Cedex, France.

e Université Paris Saclay, CNRS, CEA, Laboratoire des Solides Irradiés, Ecole Polytechnique, F-91128 Palaiseau, France

${ }^{f}$ Université Paris Saclay, CNRS, Ecole Polytechnique, Laboratoire de Physique de la Matière Condensée, F-91128 Palaiseau, France.

${ }^{g}$ Equipe de Recherche et Innovation en Electrochimie pour l'Energie ICMMO, UMR 8182, CNRS, Université Paris Sud / Université Paris-Saclay F-91405 Orsay Cedex, France.

*email: sophie.le-caer@cea.fr

\section{Abstract}

In the context of energy transition, irradiation is a powerful tool to mimic quickly the modification of electrode materials upon charge/discharge cycles in lithium-ion batteries. In this study, the evolution of the surface of silicon nanoparticles upon irradiation in two electrolytes, containing or not fluoroethylene carbonate (FEC), was studied. In the presence of FEC, irradiation leads to the formation of a homogeneous layer of a few nanometers thick and covering the whole surface of the nanoparticles. The formation of an artificial solid electrolyte interphase (SEI) layer through radiolysis is thus achieved. Without FEC, only patches of degradation products are formed on the nanoparticles surfaces for the same irradiation dose. In the absence of FEC, $\mathrm{Li}_{x} \mathrm{PF}_{\mathrm{y}} \mathrm{O}_{\mathrm{z}}$ salts are formed. In the presence of $\mathrm{FEC}, \mathrm{Li}_{\mathrm{x}} \mathrm{PO}_{\mathrm{y}}, \mathrm{LiF}$ and $\mathrm{Si}-\mathrm{F}$ bonds are generated. In both cases, the interphase contains $\mathrm{Li}_{2} \mathrm{CO}_{3}$ and a polymer containing ethylene carbonate units. Slightly different polymers are formed at the surface of nanoparticles in presence or absence of FEC, i.e. more cross-linked in the former case. The 
elastometric properties of the polymer formed in presence of FEC is thought to be responsible for the formation of the homogeneous layer on the Si surfaces, leading to the generation of an artificial solid SEI through the radiolysis process. This SEI prevents however the efficient transfer of $\mathrm{Li}^{+}$ions and more work is required to optimize its intrinsic (electro)chemical properties.

\section{Introduction}

Environmental issues due to the extensive use of fossil fuels create an ever increasing pressure to find efficient energy storage devices for intermittent energy sources. In this context, lithium-ion batteries (LIBs) are very attractive ${ }^{1,2}$ as they display high energy density and long cycle life in comparison to other rechargeable systems. ${ }^{3,4}$ In general, LIBs are composed of a carbonaceous anode, a lithiated transition metal oxide cathode, an organic liquid electrolyte and a separator. ${ }^{5}$ The relatively low capacity of graphite based anodes (370 $\mathrm{mAh} \cdot \mathrm{g}^{-1}$ ) is one factor limiting the energy that can be stored by the device. ${ }^{6,7}$ Among the various anode replacements, silicon appears as a promising material, ${ }^{7}$ with a theoretical gravimetric capacity roughly ten times higher than that of graphite $\left(\sim 3580 \mathrm{mAh} \cdot \mathrm{g}^{-1}\right)^{8}$. Upon lithiation/delithiation however, silicon undergoes large volume changes (> $300 \%$ ), resulting in significant stress and cracking of the solid electrolyte interphase (SEI) ${ }^{9}$. This cracking leads to the exposure of bare silicon formation of more SEI and ultimately to device failure. ${ }^{7}$ In order to overcome these issues, several solutions have been investigated: i) reducing the size and synthesizing silicon materials at nanometric scale, which has provided encouraging results in terms of capacity and cycle life, as nanometric silicon reduces mechanical stresses and accommodates the volume changes that arise during cycling, thus stabilizing the SEI; ${ }^{10-13}$ ii) studying new electrolytes and additives; ${ }^{14}$ iii) working on different functional binders and on electrode design and fabrication. ${ }^{15}$ The recent efforts performed to try to obtain a stable SEI layer on silicon are summarized in a recent review. ${ }^{15}$ One way to enhance the mechanical stability of the SEI consists for instance in adding a compound prone to polymerization in the electrolyte, such as fluoroethylene carbonate (FEC). ${ }^{16-18}$ The combination of nanometric silicon with new electrolytes or electrolytes containing additives provides a pathway to obtain lithium-ion batteries with improved performances.

Recently, we demonstrated that radiolysis, arising from the interaction between ionizing radiation and matter, offers an elegant method to study ageing processes of LIBs 
electrolytes in an accelerated manner, i.e., in minutes and days vs weeks and months for conventional charge/discharge cycling. ${ }^{19-22}$ Indeed, the primary species formed in the electrolyte are similar in both processes, but radiolysis enables delivering a significant amount of energy in a short time. Previously we irradiated suspensions of carbon nanoparticles, used as a representative graphite anode material, in an electrolyte, and proved that radiolysis generates electrolyte decomposition products chemically similar to the "natural" electrochemically formed SEI in LIBs at the surface of the carbon particles. ${ }^{20,21}$ Therefore $e x$ situ SEI formation was achieved by irradiation on carbon nanoparticles. ${ }^{23}$ Bearing this in mind, the objectives of the present work are i) to study whether radiolysis generates an artificial SEI layer on silicon prior to electrochemical cycling; and ii) to determine the role of FEC, a common additive with Si electrodes, in the formation of such an artificial SEI layer.

\section{Experimental section}

\section{Preparation and characterization of silicon nanoparticles}

Silicon nanoparticles were prepared by laser pyrolysis as described previously. ${ }^{24}$ Briefly, a Trumpf PRC $2800 \mathrm{CO}_{2}$ laser operating at $10.6 \mu \mathrm{m}$ wavelength with 870 Watt power was used for the decomposition of silane $\left(\mathrm{SiH}_{4}\right)$ (Messer UHP grade, 99.99\%), resulting in the formation of Si nanoparticles collected under air and stored in a glove box under argon atmosphere. The nanoparticles were heated at $450^{\circ} \mathrm{C}$ for $2 \mathrm{~h}$ under argon to remove residual impurities. After the thermal treatment, they consist of amorphous silicon nanoparticles with an average diameter around $15 \mathrm{~nm}$ (see TEM images recorded after the thermal treatment in Figure S1, Supporting Information) and a BET surface around $115 \mathrm{~m}^{2} \cdot \mathrm{g}^{-1} . \mathrm{X}$ ray diffraction and Raman characterization of similar nanoparticles can be found in Sourice et al. ${ }^{25}$.

\section{Irradiation treatment}

Thermally treated nanoparticles (1\% w) were dispersed in the electrolytes, i.e., 50/50 (v/v) ethylene carbonate (EC)/diethyl carbonate (DEC) mixture containing $\mathrm{LiPF}_{6} 1 \mathrm{M}$ or the same EC/DEC mixture containing $\mathrm{LiPF}_{6} 1 \mathrm{M}$ with addition of 2 \% FEC (Sigma-Aldrich, anhydrous grade, purity > 99 \%). The dispersion was performed in a glove box under argon atmosphere. About $1.3 \mathrm{~mL}$ of of the solution was poured into a glass ampoule and subsequently outgassed by argon bubbling for $30 \mathrm{~min}$. The ampoules were outgassed three times and filled 
with argon 6.0 (99.9999\%) at 1.5 bar. The irradiation of the samples was carried out with a panoramic ${ }^{60} \mathrm{Co} \gamma$ source. To avoid sedimentation or agglomeration of nanoparticles during irradiation experiments, the samples were continuously stirred using a specially designed sample holder. They were irradiated at a dose rate ranging between 42 and $56 \mathrm{~Gy} \cdot \mathrm{min}^{-1}$ (1 Gy $=1 \mathrm{~J} \mathrm{~kg}^{-1}$ ) depending on the irradiation position on the sample holder. The dose rate was

determined by using the aqueous Fricke dosimeter. ${ }^{26}$ After irradiation, the nanoparticles were separated by centrifugation (3000 g, $5 \mathrm{~min}, 20^{\circ} \mathrm{C}$ ), rinsed three times with $\mathrm{DEC}$, dried under vacuum for $16 \mathrm{~h}$, and stored under argon before subsequent characterizations and electrochemical experiments.

\section{Microscopy}

Transmission Electron Microscopy (TEM) experiments were performed using a field emission gun JEOL JEM-2010F microscope operating at $200 \mathrm{kV}$ with a high resolution polar piece $(\mathrm{Cs}=1.0 \mathrm{~mm}, \mathrm{Cc}=1.4 \mathrm{~mm}$, point resolution $=0.24 \mathrm{~nm})$ equipped with a Gatan ORIUS SC200 detector. Chemical mapping was performed using a FEI Titan Themis probe-corrected microscope operating at $200 \mathrm{kV}$ and equipped with a High Angle Annular Dark Field (HAADF) Scanning Transmission Electron Microscopy (STEM) module and SuperX EDX detector system. The probe current was $150 \mathrm{pA}$ with a probe size of $0.1 \mathrm{~nm}$ at Full Wave Half-Maximum. EDX acquisition was performed in 20 minutes, and spectra were deconvoluted by the Cliff-Lorimer method to extract elemental contributions ( $\mathrm{C} \mathrm{K \alpha} 0.277$ $\mathrm{keV}$, O K $\alpha 0.525 \mathrm{keV}, \mathrm{F} \mathrm{K} \alpha 0.677 \mathrm{keV}$, Si K $\alpha 1.739 \mathrm{keV}$ and P K $2.013 \mathrm{keV}$ ).

STEM images and Electron Energy Loss Spectroscopy (EELS) spectra were recorded using a FEI Cs-corrected Titan microscope running at an accelerating voltage of $200 \mathrm{kV}$. EELS spectra were collected in STEM mode with a Gatan Imaging Filter using a dispersion of 0.2 $\mathrm{eV}$ per channel and a $2 \mathrm{~mm}$ aperture. In such conditions, the energy resolution was $1.2 \mathrm{eV}$ according to the zero loss peak full width at half-maximum. Acquisitions were done in cumulative mode with a total acquisition time ranging between 0.5 and $1.0 \mathrm{~s}$.

\section{Ion beam measurements}

Nuclear elemental analysis measurements were carried out at the nuclear microprobe of the CEA-Paris Saclay, using a $3 \times 3 \mu \mathrm{m}^{2}$ proton beam of $2600 \mathrm{keV}{ }^{27}$ These nuclear techniques are 
based on the strong interaction of $\mathrm{MeV}$ energy ions with matter. The three techniques RBS, PIXE and PIGE (for respectively Rutherford Backscattering Spectrometry, Particle Induced X-Ray Emission and Particle Induced Gamma Ray Emission) were simultaneously recorded. Spectrometry of these photons and particles allows the local concentrations of the different elements in the samples under study.

In order to detect all particles, the analysis chamber is equipped with several detectors. The RBS detector was positioned at $170^{\circ}$ with respect to the beam direction. It enabled collecting the backscattered particles. A $90 \mathrm{~mm}^{2}$ Ge detector was used for X-ray collection at $45^{\circ}$ and a HP-Germanium detector installed at $0^{\circ}$ was used to detect emitted $\gamma$-rays.

For the ion beam analysis, the silicon nanoparticles (non-irradiated and irradiated) were deposited on the surface of a carbon conductive tab inside a glovebox. The samples were rapidly mounted in the analysis chamber, under secondary vacuum $\left(10^{-7} \mathrm{mbar}\right)$.

PIXE and PIGE are two complementary techniques particularly suited to measure light element content. They require a minimal sample preparation and can yield a detection limit down to a few ppm. In this work, the PIXE technique gave access to the contribution of Si and P elements while $\mathrm{Li}$ and $\mathrm{F}$ content was determined using the PIGE method.

More details about these techniques can be found in the Supporting Information.

\section{Attenuated-total-reflection (ATR) infrared spectroscopy experiment}

Fourier Transform Infrared (FT-IR) spectra of the nanoparticles were acquired by multipleinternal-reflections spectroscopy. The ATR spectra were recorded using a Bomem MB100 FT-IR spectrometer equipped with a liquid-nitrogen cooled HgCdTe (MCT) photovoltaic detector. Spectra were recorded with a p-polarized infrared beam over the 950-4000 $\mathrm{cm}^{-1}$ spectral range for $\mathrm{Si}(111)$ based ATR prisms (limited by the ATR crystal). The nanoparticles were pressed against the short side of the ATR prism using a poly-trifluorochloroethylene (PTFCE) plate. Using this procedure, the spectroscopy is not quantitative. Indeed, the nanoparticle surface concentration and the number of useful reflections of the infrared beam depend on the dispersion of the nanoparticle at the prism surface, which is quite difficult to control especially in view of the electrostatic-sensitive character of the nanoparticle powder. The absorbance was computed against a reference state where no particle was present. Two experiments were recorded for obtaining the reference state: one with the PTFCE plate pressed on the silicon prism, and one without the plate. The reference state was then obtained as the linear combination of the two recorded spectra. This allows efficient removal of the PTFCE contribution in the computed absorbance (especially the two $v_{\mathrm{C}-\mathrm{F}}$ sharp peaks at 1150 
and $1205 \mathrm{~cm}^{-1}$ ). The infrared chamber was kept under constant nitrogen purge during the acquisition of the spectra in order to avoid any atmospheric perturbations.

\section{Electrochemical characterization}

Electrodes were prepared by mixing silicon nanoparticles (80 wt\%), conductive carbon black (Super P, $10 \mathrm{wt} \%$ ) and binder (polyvinylidene difluoride binder, PVDF, $10 \mathrm{wt} \%$ ) using nmethyl-2-pyrrolidone (NMP) as solvent. The mixture was deposited on copper foil using a doctor blade at $100 \mu \mathrm{m}$ thickness. The coated electrode was dried in a vacuum oven for $12 \mathrm{~h}$ at $80{ }^{\circ} \mathrm{C}$ to evaporate NMP and cut in to circular discs used as an electrode for electrochemical measurements.

For galvanostatic tests, all manipulations were performed in an argon filled glovebox and the electrodes were pressed at 1 ton each. The experiments were performed in CR2032 coin cells with a Celgard 2400 polypropylene separator. EC:DEC 1:1 w/2\% FEC with $1 \mathrm{M} \mathrm{LiPF} 6$ was used as the electrolyte in these tests, with Li foil as counter electrode. Galvanostatic tests were performed using a BCS-805 cycler (Biologic) working with BT Lab software. Cells were cycled at $\mathrm{C} / 20$ between $0 \mathrm{~V}$ and $3 \mathrm{~V}$ vs. $\mathrm{Li}^{+} / \mathrm{Li}$, with a 60 hour limit imposed on the test. The capacity of Si was estimated to be $3600 \mathrm{~mA} \cdot \mathrm{h} \mathrm{g}^{-1}$. The loading on the $1.54 \mathrm{~cm}^{2}$ electrode was about $2.5 \mathrm{mg}$ of active material. The current density corresponding to C/20 was then around $0.29 \mathrm{~mA} . \mathrm{cm}^{-2}$.

Electrochemical impedance spectroscopy (EIS) measurements were carried out at room temperature using a Biologic VMP3 electrochemical workstation, in the frequency range from $83 \mathrm{kHz}$ to $33 \mathrm{mHz}$, with a sinusoidal voltage signal amplitude of $10 \mathrm{mV}$. The test cells were similar to those used in the galvanostatic tests, except a symmetrical configuration was used. The equilibrium potential was considered to be reached when the drift in open circuit voltage remained less than $0.1 \mathrm{mV}$ for 1 hour. Fitting of the impedance spectra was performed with the Zplot ${ }^{\circledR}$ software from Scribner Associates. 


\section{Results and discussion}

Characterization of the evolution of the surface of the silicon nanoparticles with irradiation

Ion beam analysis

Figure 1 shows the evolution of each elemental contribution (PIXE: Si and P, PIGE: F and Li elements) for the non-irradiated Si nanoparticles (NPs) and those irradiated at $200 \mathrm{kGy}$. We consider that all samples are mainly composed of silicon nanoparticles. The stopping power of non-irradiated and irradiated samples is thus very close to each other. The elemental contents are then proportional to the area corresponding to the peak. Each spectrum is normalized with respect to the Si signal. Deduced from the data presented in Figure 1, Figure 2 presents the evolution of the area of $\mathrm{Li}, \mathrm{P}$ and $\mathrm{F}$ before and after irradiation. These figures show that for all electrolyte solvents, residues of the electrolyte are found independently of irradiation. More fluorine is detected on the surfaces after exposure to the electrolyte containing FEC. After irradiation at $200 \mathrm{kGy}$, the contribution of P, F and Li are globally increased as compared to the non-irradiated samples. 

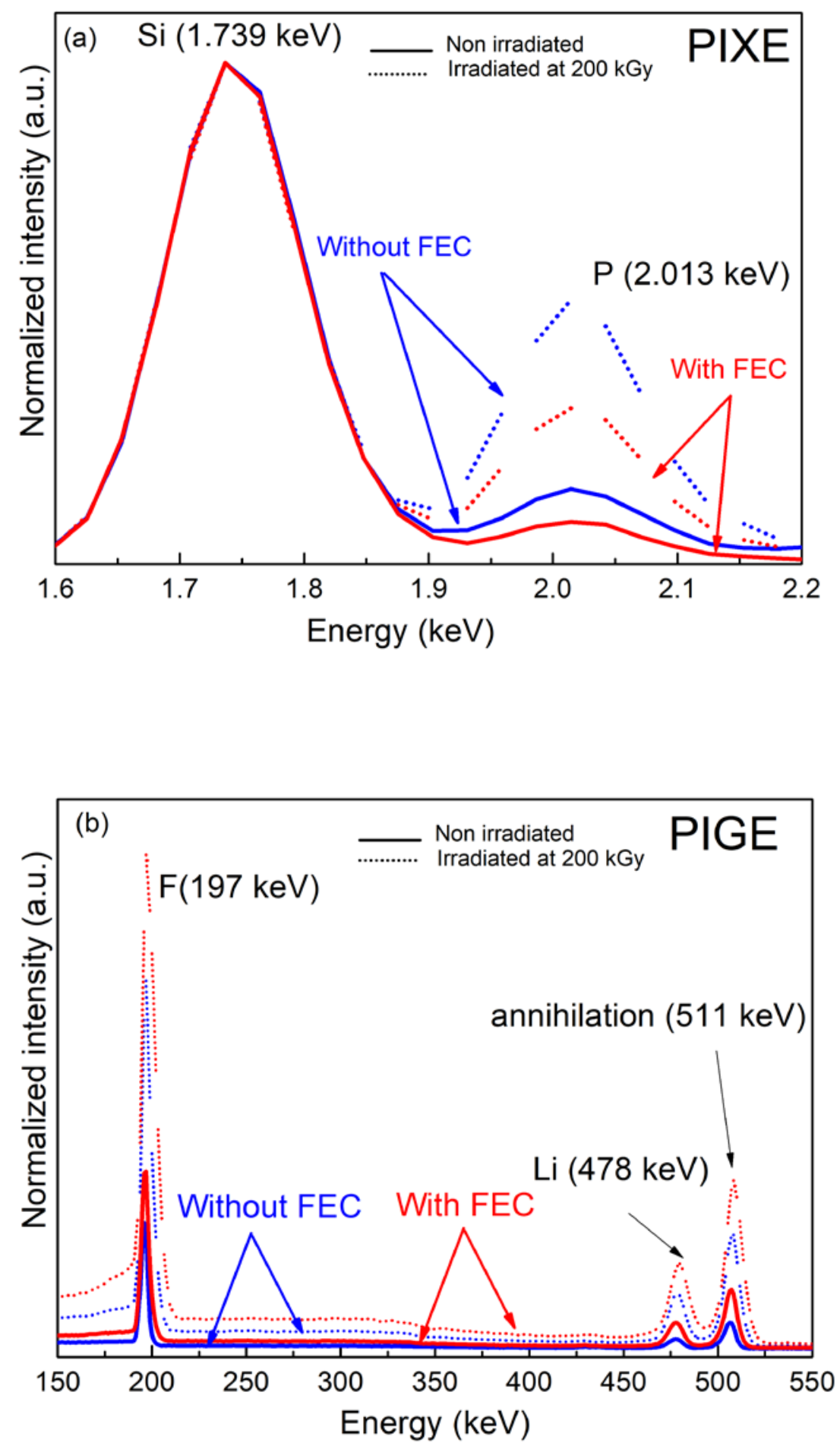

Figure 1. Evolution of the PIXE (a) and PIGE (b) spectra of the Si NPs/electrolyte system before (line) and after irradiation at $200 \mathrm{kGy}$ (dotted line). Blue and red colors are used for the samples exposed/irradiated to/in electrolytes without or with FEC, respectively. For the sake of comparison, each spectrum is normalized with respect to the Si signal. 


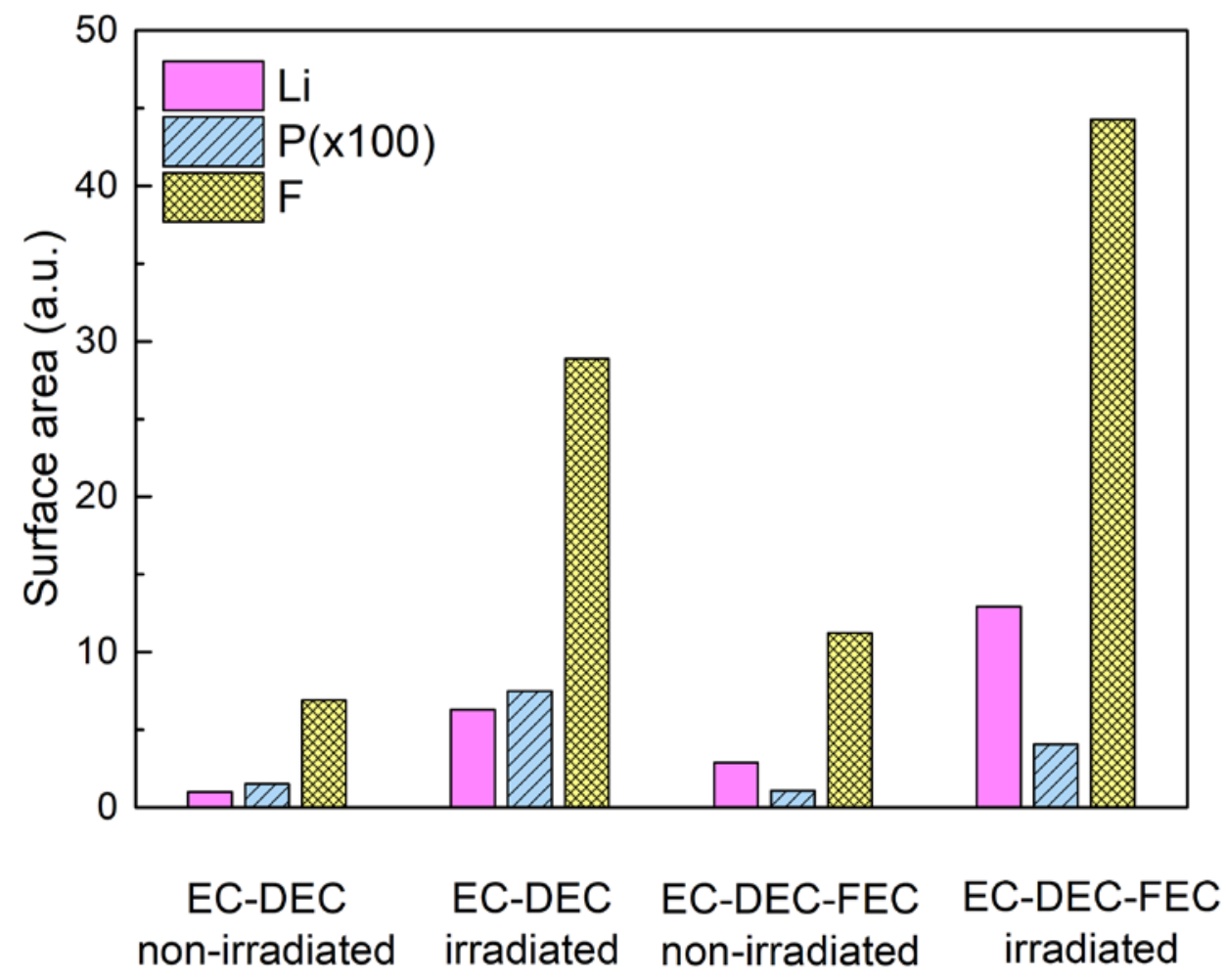

Figure 2. Evolution of the surface area corresponding to the elemental peak (PIXE P 2.013 $\mathrm{keV}$; PIGE F: $197 \mathrm{keV}$ and Li: $478 \mathrm{keV}$ ) for the Si NPs/electrolyte systems (with and without FEC) before and after irradiation at $200 \mathrm{kGy}$.

Infrared spectroscopy to reveal the nature of the chemical bonds

The evolution of the silicon-nanoparticle surface chemistry at increasing doses was investigated using IR spectroscopy. The corresponding IR spectra are displayed in Figure 3 (Figure 3a and 3b for the electrolyte without/with FEC, respectively).

No species are detected on the surface of the silicon nanoparticles before irradiation in the 900-2000 $\mathrm{cm}^{-1}$ wavenumber range. The features observed in this spectral range after irradiation are due to compounds deposited on the surfaces, and thus attributed to the formation of a solid electrolyte interphase (SEI).

Globally, after irradiation, the position of the detected bands is the same in both samples and most of the vibrational features change in the same proportions with the dose. Indeed, the spectra displayed in Figures 3a and 3b look very similar. This suggests that the SEI formed upon irradiation on the surface of the nanoparticles shares many common features. These observations are consistent with previous studies on Li-ion batteries, suggesting that the SEI 
is similar in structure in an electrolyte containing a low concentration of FEC to the SEI generated in FEC free electrolytes. ${ }^{28}$

In both cases, the main features detected around 975, 1079, 1164, 1395, 1483, 1776 and 1807 $\mathrm{cm}^{-1}$ are similar, in terms of positions, to those reported in the case of ethylene carbonate. ${ }^{29-31}$ In the present case, the first features are assigned to ring stretching, out-of-phase $\mathrm{CH}_{2}$ rocking, $\mathrm{CH}_{2}$ twisting, $\mathrm{CH}_{2}$ wagging and $\mathrm{CH}_{2}$ scissoring, respectively. ${ }^{32}$ The band at $1807 \mathrm{~cm}^{-1}$ is ascribed to $\mathrm{C}=\mathrm{O}$ stretching and that at $1776 \mathrm{~cm}^{-1}$ to an overtone of the ring breathing mode enhanced by Fermi resonance with the $\mathrm{C}=\mathrm{O}$ stretching. ${ }^{32}$ The similarity between the infrared bands of EC and those measured in the present work suggests that a polymer is formed on the surface of the nanoparticles and shares common features with ethylene carbonate. It is worth pointing out that cyclic carbonates are more reactive than linear ones. ${ }^{16}$ Therefore the features we detect here are mostly due to the cyclic compound (EC). Poly(vinyl carbonate) (poly(VC)) appears as a good candidate. ${ }^{33}$ Under ionizing radiation, EC will lead to the formation of the EC(-H) ${ }^{\bullet}$ radical. $^{22}$ This radical will convert to vinylene carbonate, after ejection of a hydrogen atom. $^{34}$ After reduction, vinylene carbonate will polymerize. Notably, poly(VC) exhibits infrared bands at 1803, $1776 \mathrm{~cm}^{-1}, 1075 \mathrm{~cm}^{-1}$ and at $1164 \mathrm{~cm}^{-1} \cdot 30,35$ Shkrob et al. showed that the radiolytically induced polymerization of ethylene carbonate can proceed either through an anionic or radical route. ${ }^{34}$ In the latter case, the polymer exhibits ethylene carbonate units (i.e., the same units as in poly(VC)) whereas in the former case it exhibits ethylene oxide units ($\left.\mathrm{CH}_{2} \mathrm{CH}_{2} \mathrm{O}-\right)$ and linear carbonate units. ${ }^{34}$ Both routes can coexist and the structure can be even more complex, with the formation of $\mathrm{C}-\mathrm{CH}(\mathrm{X})-\mathrm{C}$ branches, $\mathrm{X}$ being $-\mathrm{OH}$ group or a carbonate group. ${ }^{34}$ In our conditions, the radical route appears largely predominant since no infrared signal is found in the $1600-1750 \mathrm{~cm}^{-1}$ range typical of organic linear carbonates and lithium carbonate compounds. ${ }^{36}$ In the $1000-1200 \mathrm{~cm}^{-1}$ wavenumber range, it is also difficult to isolate some contributions of C-O-C stretching modes of ethylene oxide units ${ }^{37}$ or components due to ROLi (alkoxy) species, ${ }^{38}$ which might however be masked by the main signals already described if the corresponding species are present in low quantities. The infrared fingerprint of the polymeric layer formed at the surface is then close to that of poly(VC). Specifically, it seems that, among the various radiolysis processes for FEC decomposition considered in the literature, ${ }^{39}$ the one going through $\mathrm{F}$ loss radical should be the most prevalent under our conditions as no IR band at $1835 \mathrm{~cm}^{-1}$ can be detected in the spectra of Figure 3b. Such a band is quite specific of FEC, ${ }^{40}$ and its absence indicates that Fsubstituted cyclic units are not detectable in the formed polymer. 
The presence of the $\mathrm{Li}_{2} \mathrm{CO}_{3}$ can also be looked for, which according to the literature is expected to give contributions around 1480 and $1420 \mathrm{~cm}^{-1} \cdot{ }^{41}$ For both electrolytes, one notices the presence of a tail or a shoulder on the high-frequency side of the band at $1395 \mathrm{~cm}^{-1}$, and especially in the presence of FEC (Figure 3b), which is compatible with a contribution from $\mathrm{CO}_{3}{ }^{2-}$ ions. A similar contribution at $1480 \mathrm{~cm}^{-1}$ is difficult to analyse, due to the overlap with the aforementioned peak at $1483 \mathrm{~cm}^{-1}$. In all, the formation of $\mathrm{Li}_{2} \mathrm{CO}_{3}$ upon irradiation on the surface of the silicon nanoparticles is compatible with the recorded spectra, but it is likely formed in small quantities.

It appears surprising that $\mathrm{ROCO}_{2} \mathrm{Li}$ compounds are not detected here (as no corresponding characteristic band is observed in the $1600-1700 \mathrm{~cm}^{-1}$ wavenumber range ${ }^{42}$ ) since such compounds were detected by XPS at the surface of carbon nanoparticles after irradiation of a suspension of these nanoparticles in a EC/DEC/LiPF 6 mixture. ${ }^{23}$ Picosecond pulse radiolysis of EC/DEC mixtures provides evidence for the formation of the $\mathrm{EC}^{\bullet-}$ radical anion, ${ }^{22}$ which reacts with another $\mathrm{EC}^{\bullet-}$ radical anion to form ethylene and ethylene dicarbonate dianion ( ${ }^{-} \mathrm{OCOCH}_{2} \mathrm{CH}_{2} \mathrm{OCOO}^{-}$). This latter compound precipitates in the presence of lithium as solid lithium ethylene dicarbonate ( $\left.\mathrm{Li}_{2} \mathrm{EDC}\right) .{ }^{43}$ Obviously a fingerprint of this process is not observed here. However, other works suggest that in the presence of $\mathrm{LiPF}_{6}$, no carbonate compounds are detected, and that the presence of $\mathrm{Li}_{2} \mathrm{CO}_{3}$ can be mainly attributed to residual water molecules. ${ }^{44,45}$ Marom et al. suggests ${ }^{44}$ that HF (generated also by radiolysis, see Ortiz et $a .^{20}$ ) reacts with $\mathrm{ROCO}_{2} \mathrm{Li}$ to produce $\mathrm{LiF}$ and $\mathrm{ROCO}_{2} \mathrm{H}$, the latter being soluble in the liquid phase. This explanation seems to be the most reasonable as the volume of the solution (electrolyte) used here is large as compared to the volume of the nanoparticles.

Some differences can also be observed when comparing the shape of IR spectra recorded after irradiation in the presence or absence of FEC. This suggests that FEC induces the formation of a polymer that may be similar to that obtained without FEC, but with some distinct features. The most striking difference is that the ratio of the intensity of the band at $1805 \mathrm{~cm}^{-1}$ to the intensity of the band at $1775 \mathrm{~cm}^{-1}$ increases in the presence of FEC. Since the band at $1775 \mathrm{~cm}^{-1}$ is due to an overtone of the breathing mode of the cyclic ethylene carbonate unit, and that such a mode is known to be sensitive to the association of the unit to a $\mathrm{Li}^{+}$cation, ${ }^{32}$ the change in the latter ratio could be a fingerprint of a distinct capability of the polymer formed upon irradiation to accommodate $\mathrm{Li}^{+}$ions. Note that in the work of Shkrob et al., the authors suggest that the polymer formed upon irradiation by reduction of FEC would be much more cross-linked than that obtained in the absence of FEC, which would give it elastomeric properties, ${ }^{39}$ but could also affect its capability of accommodating $\mathrm{Li}^{+}$ions. This is also 
confirmed by a more recent work. ${ }^{46}$ The authors have indeed shown, using NMR experiments, that in EC-based electrolytes, linear poly(ethylene oxide) (PEO) polymers are formed. ${ }^{46}$ In pure FEC with $1 \mathrm{M} \mathrm{LiPF}_{6}$, this polymer is heterogeneous and consists mainly of cross-linked PEO. $^{46}$ The authors suggest that the mechanical properties of these cross-linked polymers may be different from their linear counterparts, as they can be more elastic. ${ }^{46}$

Second, the global shape of the infrared bands recorded in the $1000-1500 \mathrm{~cm}^{-1}$ wavenumber range is slightly different for both electrolytes. The presence of this more cross-linked polymer could explain the changes observed between Figures 3a and $3 b$ in this spectral range. In conclusion, the IR spectra evidence that after irradiation in one given electrolyte, the compounds formed on the surface remain the same, whatever the irradiation dose. The compounds formed after irradiation in both electrolytes are globally the same, but some discrepancies exist and are mostly attributed to the difference in the polymers formed on the surfaces.

Our experimental set-up does not have access to wavenumbers lower than $900 \mathrm{~cm}^{-1}$, typical of compounds containing fluorine or phosphorous atoms, but these latter atoms are revealed by the other techniques as described in the following.

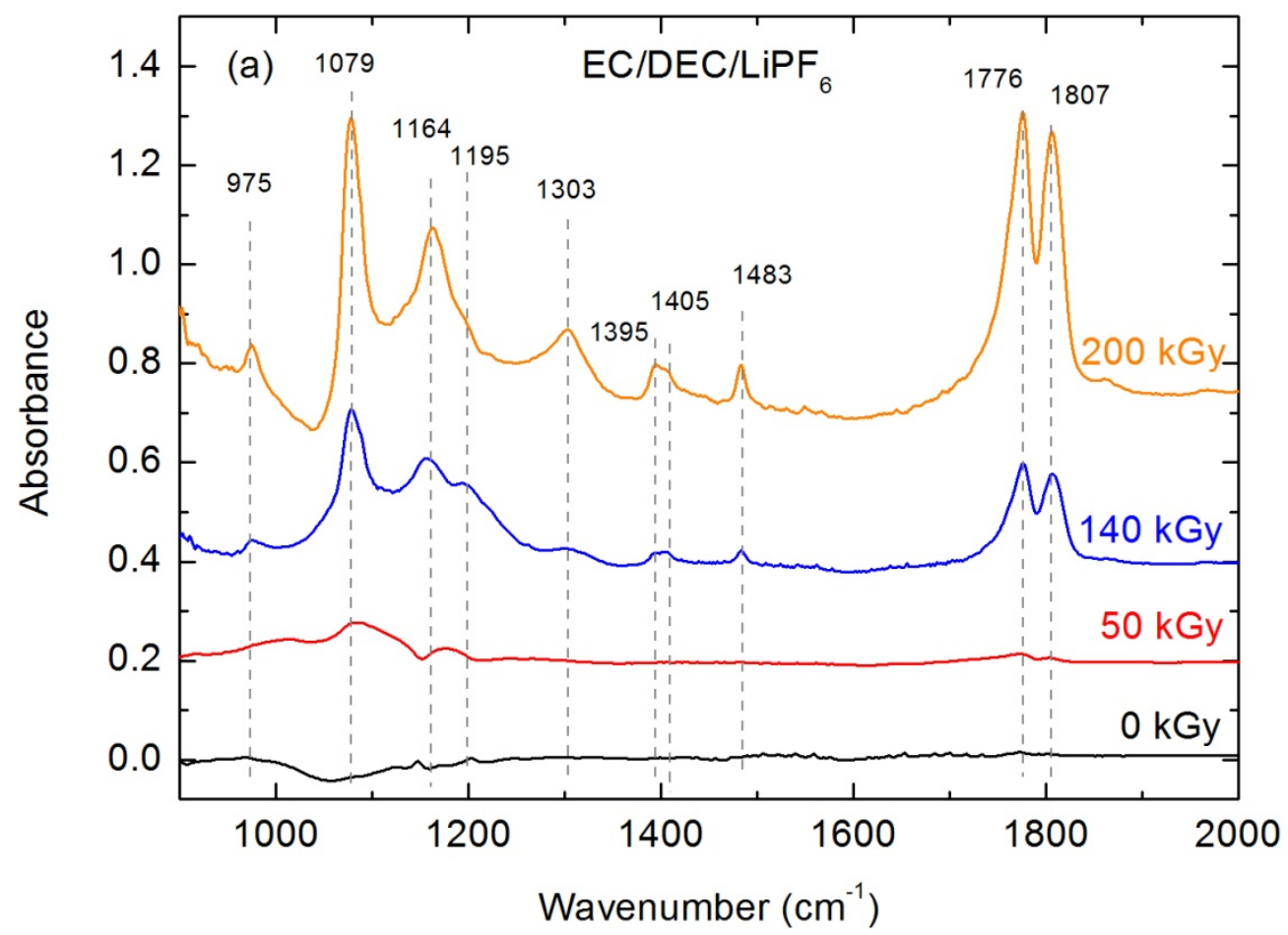




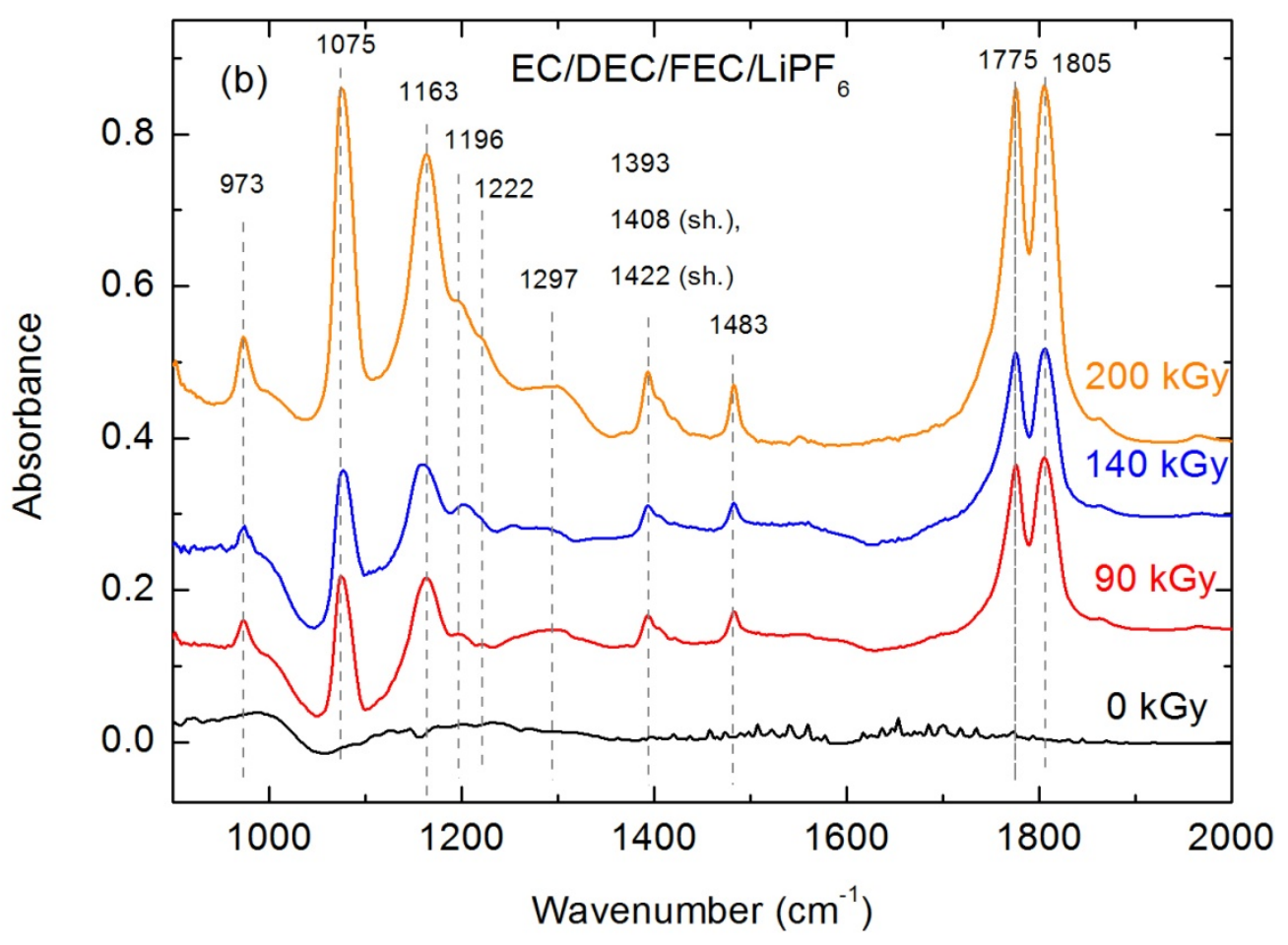

Figure 3. Evolution of IR spectra in the $900-2000 \mathrm{~cm}^{-1}$ wavenumber range before and after irradiation at increasing doses for the Si NPs/electrolyte system: (a) EC/DEC/LiPF 6 ; (b) EC/DEC/FEC/LiPF 6 . "sh." stands for shoulder. The characteristic wavenumbers are displayed on the figures. As stated in the experimental section, no quantitative information can be obtained from these spectra. The spectra were thus rescaled for the sake of clarity.

\section{Microscopy experiments}

In order to have further insight into the localization of the elements ( $\mathrm{Si}, \mathrm{C}, \mathrm{O}, \mathrm{P}$ and $\mathrm{F}$ ) present on the nanoparticles, EDX images were recorded under similar conditions (Figure 4 and Figure 5 after interaction with the electrolytes without or with FEC, respectively).

In the case of the NPs exposed to the electrolyte without FEC and not irradiated, the surface of the NPs is oxidized (Figure 4a). We can assume that oxidation takes place when the samples are prepared for the EDX experiments as this is performed under air. In the case of irradiated samples, the compounds present at their surface prevent the formation of Si-O bonds and similar oxidation is not observed. Residues of the electrolyte (C, P and F) are seen on the surfaces, in agreement with ion beam analysis results (Figure 2). The presence of species containing fluorine, but none of the other elements detected, suggests the formation of LiF. This compound is generated during the drying step after interaction with the

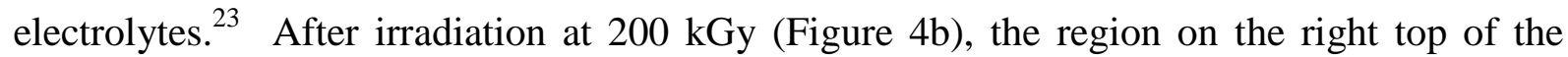


images suggests the presence of $\mathrm{O}, \mathrm{F}$ and $\mathrm{P}$ elements (and in agreement with ion beam analysis results, see Figure 2). They are not however, located on the surface of the Si NPs, as the localization of these elements does not match with that of silicon. The presence of these elements suggests the formation of $\mathrm{Li}_{\mathrm{x}} \mathrm{PF}_{\mathrm{y}} \mathrm{O}_{\mathrm{z}}$ salts already observed in the SEI during the cycling of LIBs in the absence of FEC. ${ }^{18,47} \mathrm{No} \mathrm{LiF}$ is observed in the irradiated sample, suggesting that $\mathrm{Li}_{\mathrm{x}} \mathrm{PF}_{\mathrm{y}} \mathrm{O}_{\mathrm{z}}$ salts are preferentially formed over $\mathrm{LiF}$ for this FEC-free electrolyte. The comparison of Figures 4a and 4b suggests that the amount of species containing fluorine and phosphorus elements is increased after irradiation (also consistent with the results presented in Figure 2), and deposited more uniformly on the surfaces than before irradiation.
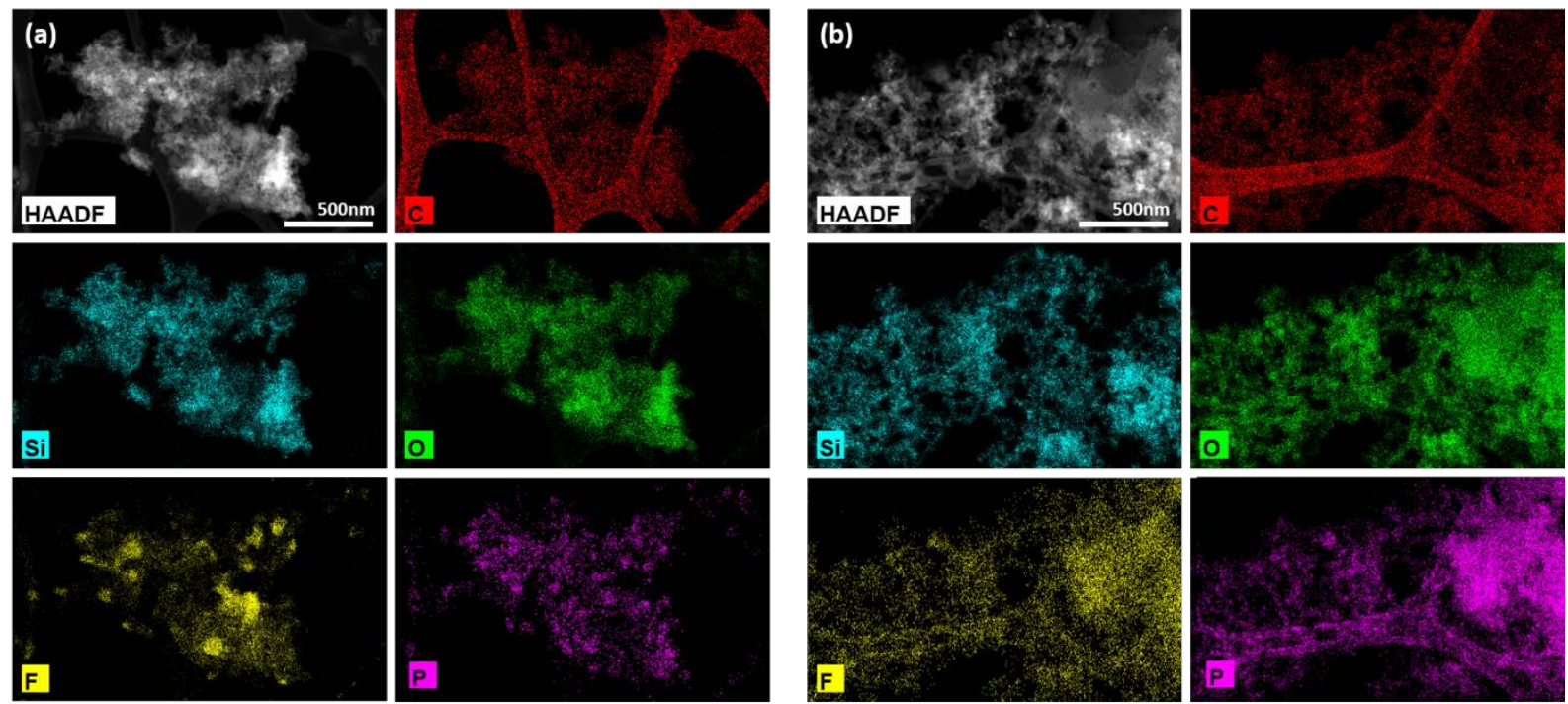

Figure 4. EDX images of the silicon nanoparticles (a) non-irradiated but exposed to $\mathrm{EC} / \mathrm{DEC} / \mathrm{LiPF}_{6}$; (b) irradiated at $200 \mathrm{kGy}$ in $\mathrm{EC} / \mathrm{DEC} / \mathrm{LiPF}_{6}$. Carbon is in red; silicon in pale blue; oxygen in green; fluorine in yellow and phosphorus in purple.

The same experiments were performed in presence of the electrolyte containing FEC (Figure 5a, non-irradiated; Figure 5b, after irradiation at $200 \mathrm{kGy}$ ). As in the previous case (non-irradiated sample), $\mathrm{LiF}$ is assumed to be formed upon drying, with also a contribution of $\mathrm{Si}$ and $\mathrm{O}$ atoms. After irradiation, the images suggest that $\mathrm{C}, \mathrm{O}, \mathrm{F}$ and $\mathrm{P}$ uniformly cover the silicon nanoparticles. Their contributions are increased when compared to the non-irradiated sample (if we except $\mathrm{LiF}$ in the non-irradiated sample). $\mathrm{C}$ and O homogeneously cover the Si NPs in agreement with the STEM-EELS experiments (Figure 6d, see below), whereas F and P appear more localized. EDX images recorded at a larger scale are given in Figure S2 in Supporting Information. As is typical from samples 
irradiated in presence of FEC, -Si-F type and LiF species are also detected. The EDX images (Figure S2) also suggest that some regions are rich in $\mathrm{Si}, \mathrm{O}$ and $\mathrm{P}$ elements. This may be due to the formation of $\mathrm{Li}_{x} \mathrm{PO}_{\mathrm{y}}$ compounds on the Si NPs. This behaviour is different from that of samples irradiated in $\mathrm{EC} / \mathrm{DEC} / \mathrm{LiPF}_{6}$ electrolyte where $\mathrm{Li}_{\mathrm{x}} \mathrm{PF}_{\mathrm{y}} \mathrm{O}_{\mathrm{z}}$ salts were observed. These conclusions are consistent with those reported by Choi et al. ${ }^{28}$ on silicon thin film electrodes.

Finally, the identification of the various species formed upon irradiation is in line with the ion beam analysis experiments, which provides evidence for an increase of lithium, fluorine and phosphorus elements upon irradiation (Figure 2).
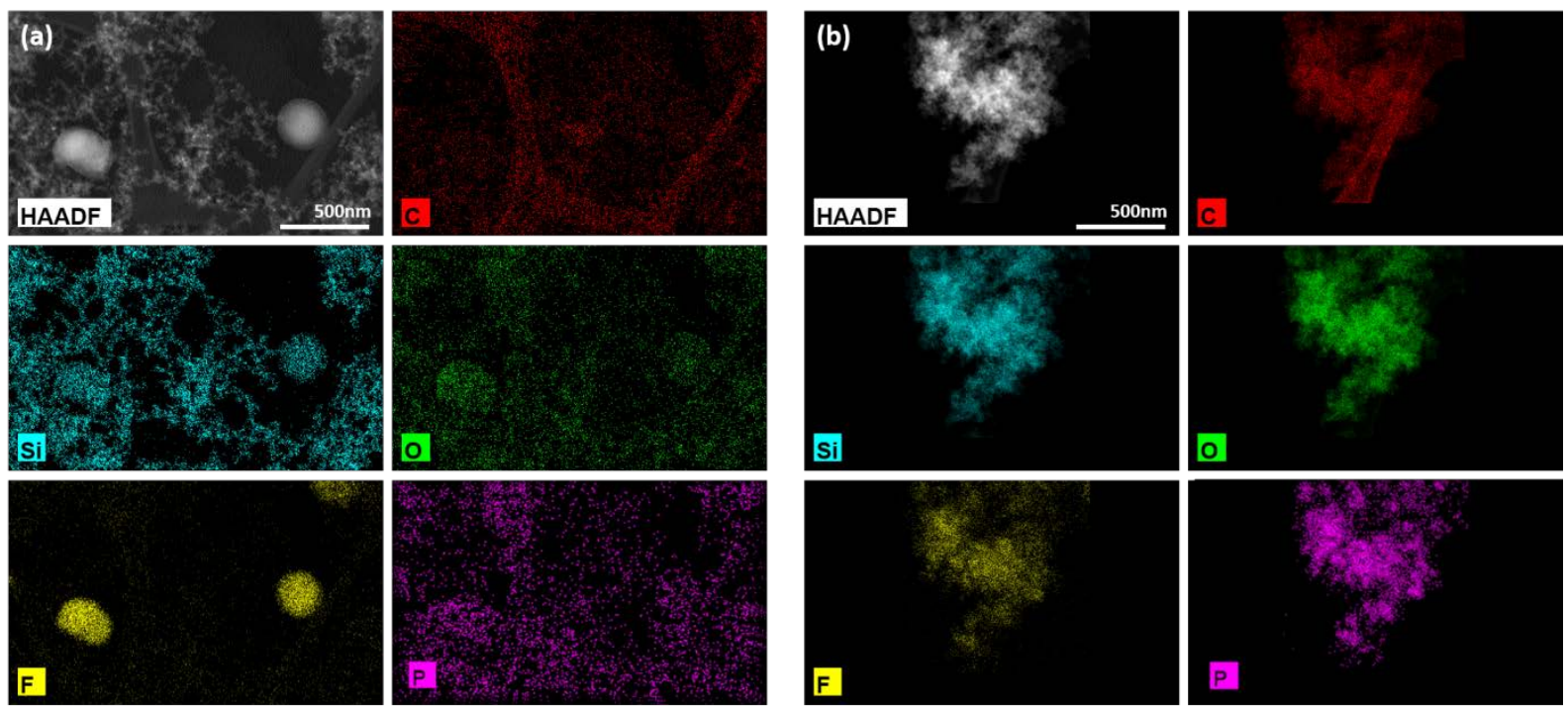

Figure 5. EDX images of the silicon nanoparticles (a) non-irradiated but exposed to EC/DEC/FEC/LiPF ; (b) irradiated at $200 \mathrm{kGy}$ in EC/DEC/FEC/LiPF . Carbon is in red; silicon in pale blue; oxygen in green; fluorine in yellow and phosphorus in purple.

The evolution of the morphology of the nanoparticles was obtained by STEM. The corresponding images of the silicon nanoparticles are displayed in Figure 6. Carbon residues appear on the silicon nanoparticles, for all electrolytes, after the cleaning and drying procedure (Figures 6a and 6c). Figure 6b shows the silicon nanoparticles, after a $190 \mathrm{kGy}$ irradiation in an EC/DEC/LiPF ${ }_{6}$ electrolyte. Non-homogeneous carbon patches are found at the surface of the nanoparticles. By contrast, at a similar dose (200 kGy), after irradiation in the electrolyte containing FEC, a homogenous layer containing carbon with a thickness of a 
few nanometers (around $2.5 \mathrm{~nm}$ ) is formed on the surface of the silicon nanoparticles (Figure 6d). These results strongly suggest that the formation of a homogeneous SEI is achieved, at this dose, on silicon nanoparticles irradiated in the presence of the EC/DEC/FEC/LiPF 6 electrolyte. These images also provide evidence for the crucial role played by the additive for the formation of a continuous layer. Together with infrared results (Figure 3), this implies that FEC favors the formation of a polymer exhibiting some special properties (Figure 6d). The elastomeric properties of the polymer formed from FEC, as reported by Shkrob et al., ${ }^{39}$ and confirmed by a recent NMR study ${ }^{46}$ which evidenced the cross-linked character of the polymer formed in FEC is in line with the full coverage of the surface of the nanoparticles in the presence of the FEC-containing electrolyte (Figure 6).

Images obtained after irradiation at a lower dose in presence of FEC can be found in the Supporting Information, Figure S3. At $110 \mathrm{kGy}$ (Figure S3b), the formation of such continuous interphase is not achieved as shown by the very different morphology compared to Figure 6d. Carbon species are first formed as patches on the surface. These patches grow and finally form a continuous interphase. Lastly, even at the $110 \mathrm{kGy}$ irradiation dose, and in the presence of the electrolyte containing the additive only, agglomerates of SEI are observed in the sample (Figure S3a). 

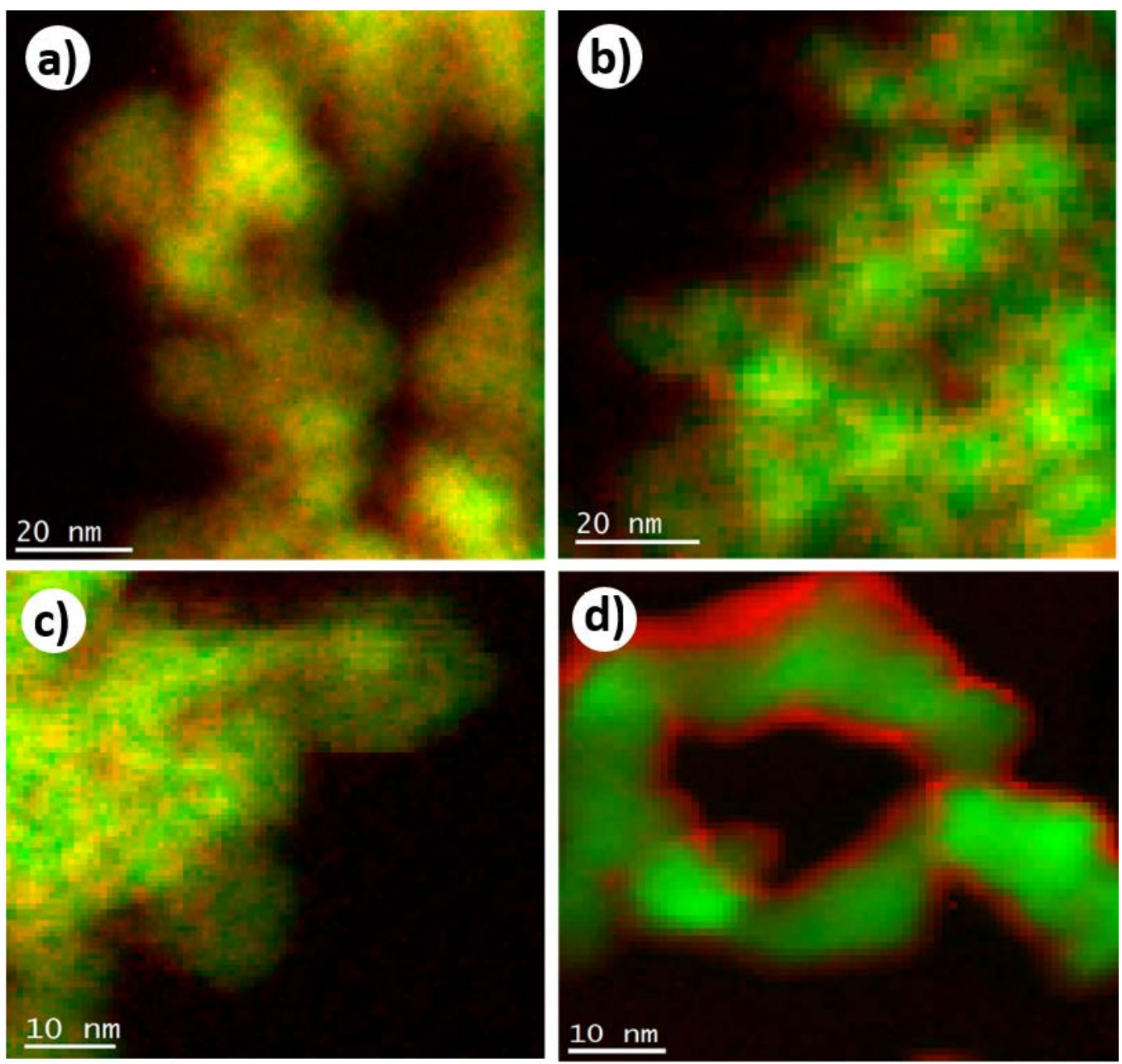

Figure 6. STEM images and EELS mapping of Si nanoparticles after (a) exposure to $\mathrm{EC} / \mathrm{DEC} / \mathrm{LiPF}_{6}$ electrolyte; (b) irradiation at $190 \mathrm{kGy}$ in a $\mathrm{EC} / \mathrm{DEC} / \mathrm{LiPF}_{6}$ electrolyte; (c) exposure to $\mathrm{EC} / \mathrm{DEC} / \mathrm{FEC} / \mathrm{LiPF}_{6}$ electrolyte; (d) irradiation at $200 \mathrm{kGy}$ in a $\mathrm{EC} / \mathrm{DEC} / \mathrm{FEC} / \mathrm{LiPF}_{6}$ electrolyte. The green color stands for silicon and the red one for carbon. The yellow color arises from regions with less carbon amount than the red ones.

\section{Electrochemical characterization}

Electrochemical impedance spectroscopy (EIS) was used to investigate the SEI formation after irradiation on silicon nanoparticles in the presence of both electrolytes (with or without FEC). The addition of FEC in alkyl carbonate electrolyte solutions is known to stabilize reversible capacities over long cycling due to the more (mechanically) stable and uniform SEI layer formed on the electrode surface. ${ }^{16}$ The quality of the SEI film on silicon nanoparticles is a key factor for reversible cycling and long-term stability. ${ }^{28}$ Impedance was measured with 
and without FEC (non-irradiated and irradiated at a dose of $200 \mathrm{kGy}$ ). The fitted data are shown in Figure 7. The Nyquist plots consist mainly of two parts, which are semicircle(s) in the high frequency region and a straight line in the low frequency region. The semicircle(s) in the high-to-medium frequency region corresponds to the interfacial processes (contact resistance with current collector, passivation layer -if any-, and charge transfer resistance), while the sloping line, in the low frequency region, is linked to a bulk process, i.e. the ions diffusion within the electrodes. The physical parameters of the electrodes are deduced from these data and reported in Table 1. From these data, it is also observed that the semi-infinite diffusion domain (Warburg) is only slightly changed in the irradiated samples as compared to the exposed ones, since the associated frequencies are quite the same (always starting below $10 \mathrm{~Hz}$ ). Galvanostatic curves also do not show polarization, which indicates that the main limitation comes from kinetics and not from mass transport (diffusion). We can thus assume that lithium diffusion is not affected by irradiation.

From the electrical equivalent circuit used for the irradiated samples (Figure 7, on the top right), it is clear that the surface of the nanoparticles irradiated in the presence of FEC are homogeneously covered, as the $\alpha_{\mathrm{f}}$ factor associated with the film pseudocapacitance $\left(Z_{\mathrm{CPE}-\mathrm{f}}=1 / \mathrm{C}_{\mathrm{f}}(\mathrm{j} \omega)^{\alpha}\right)$ is calculated to be 1 (ideal planar geometry), whereas it is 0.9 in the absence of FEC (Table 1). The SEI formed in the FEC-free solutions is thus nonhomogeneous after a $200 \mathrm{kGy}$ irradiation. In contrast, the film formed on the nanoparticle surface in the FEC-containing electrolyte after irradiation has a smooth and uniform morphology. These conclusions are consistent with the STEM observations (Figure 6).

Moreover, after irradiation, the presence of FEC increases the amount of SEI as the associated resistance, $\mathrm{R}_{\mathrm{f}}$, is increased as compared to the samples without FEC. A change in SEI chemical composition can also be seen, since the corresponding relaxation frequencies are slightly different, depending on the presence of FEC $(50 \mathrm{kHz})$ or not $(80 \mathrm{kHz})$, which is consistent with the surface analyses. These values indicate that the SEI is slightly less conductive when formed in the presence of the additive than without. The low $R_{f}$ values however show that the SEI is not insulating. The change in the SEI composition, together with a homogeneous layer, which is also thicker than in the absence of FEC, increases noticeably the charge transfer resistance $\left(R_{c t}=23 \Omega\right)$ as compared to without FEC $\left(R_{c t}=1 \Omega\right)$. Note that charge transfer is more related to chemical composition than to thickness and that the SEI layer resistance has a lower impact on the overall system impedance. 

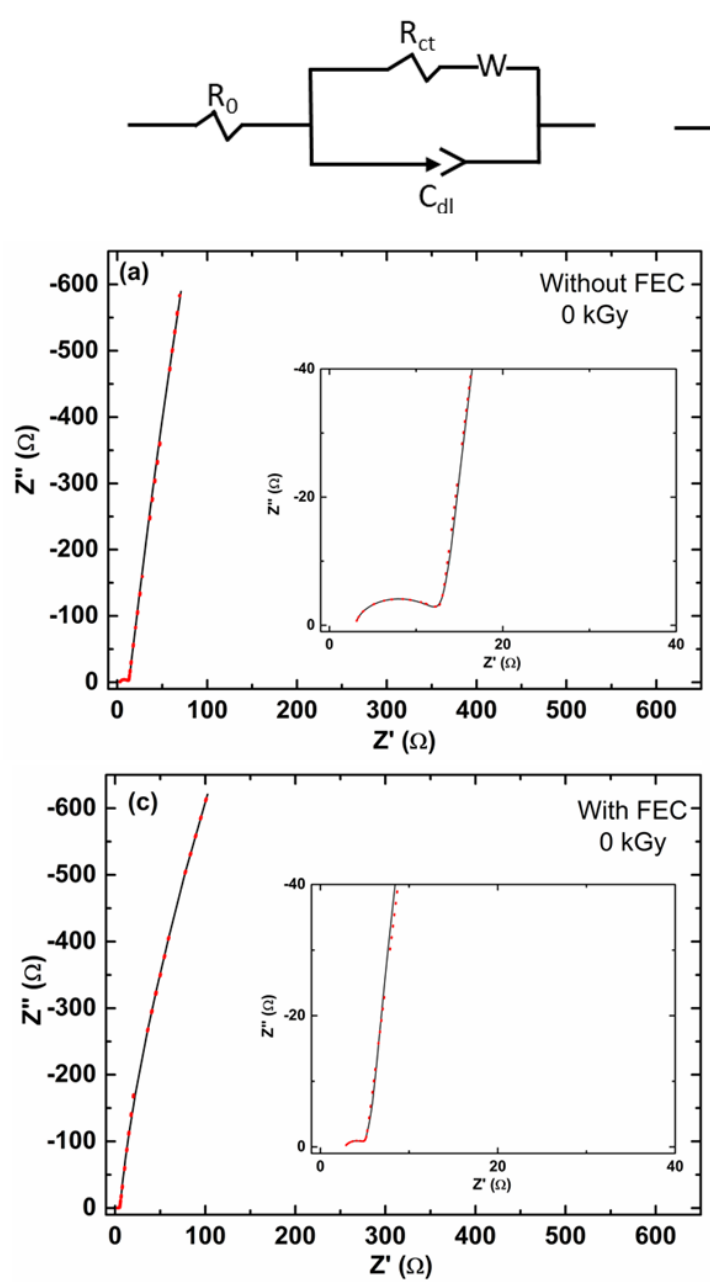
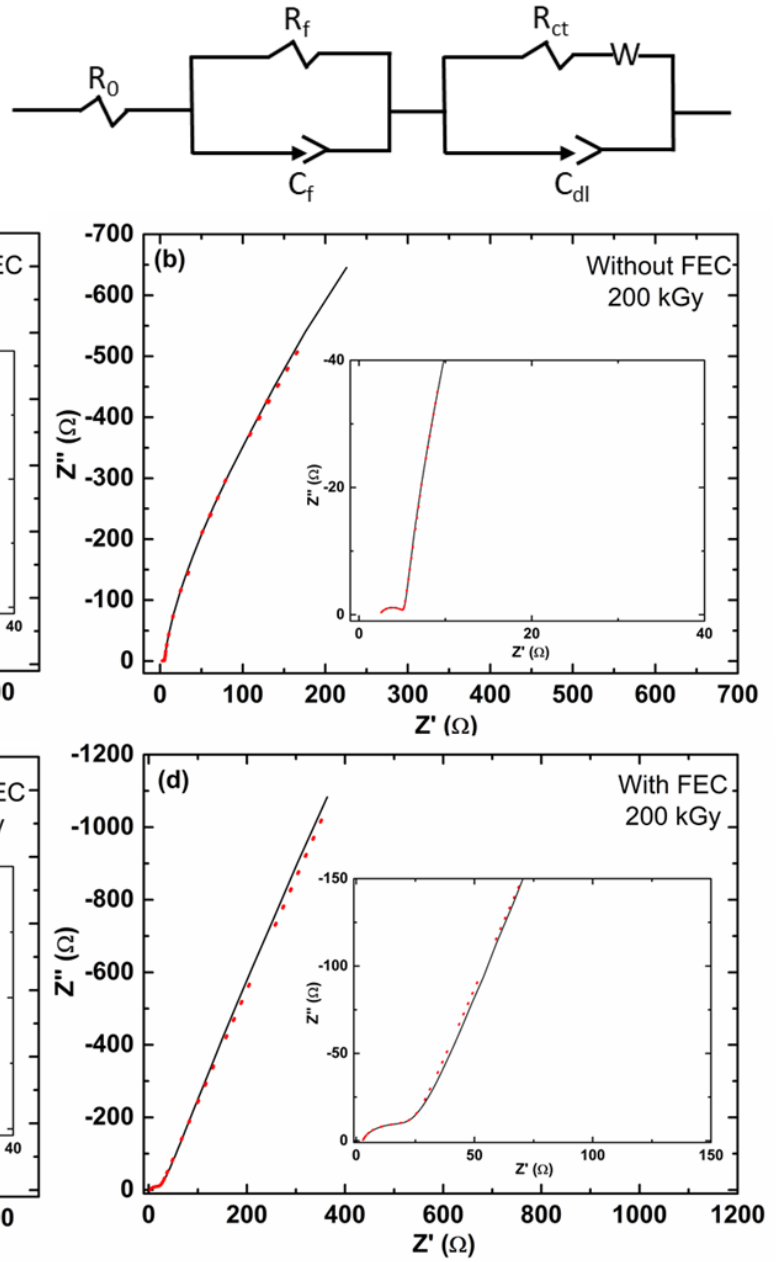

Figure 7. Electrochemical impedance spectroscopy (EIS) raw spectra of the symmetrical cells containing silicon nanoparticles before (a, c) and after (b, d) irradiation at a dose of $200 \mathrm{kGy}$ ((a and b) without FEC and (c and d) with FEC). The inset in the figures (a to d) is a focus on the lowest Z' values. The corresponding electrical equivalent circuits before (left) and after (right) irradiation are shown above. The electrical equivalent circuit contains less parameters before than after irradiation, as no SEI is observed when the samples are not irradiated. 
Table 1. Electrochemical impedance spectroscopy fitted data assigned to single electrodes containing silicon nanoparticles, for the samples exposed/irradiated to/in electrolytes without or with FEC, respectively.

\begin{tabular}{|c|c|c|c|c|c|}
\hline & & \multicolumn{2}{|c|}{ Without FEC } & \multicolumn{2}{|c|}{ With FEC } \\
\hline & & Non irradiated & $\begin{array}{c}\text { Irradiated at } \\
200 \mathrm{kGy}\end{array}$ & Non irradiated & $\begin{array}{l}\text { Irradiated at } \\
200 \mathrm{kGy}\end{array}$ \\
\hline $\begin{array}{c}\text { Contact } \\
\text { resistances }\end{array}$ & $\mathrm{R}_{0}$ & 3 & 2.5 & 3 & 3 \\
\hline \multirow[t]{2}{*}{ SEI } & $\mathrm{R}_{\mathrm{f}}$ & - & 2.2 & - & 3.5 \\
\hline & $\alpha_{f}$ & - & 0.9 & - & 1 \\
\hline \multirow{2}{*}{$\begin{array}{c}\text { Charge } \\
\text { transfer // } \\
\text { double layer }\end{array}$} & $\mathrm{R}_{\mathrm{ct}}$ & 10 & 1 & 2 & 23 \\
\hline & $\alpha_{\mathrm{dl}}$ & 0.9 & 0.9 & 0.9 & 0.9 \\
\hline
\end{tabular}

To further investigate the functionality of the SEI generated during irradiation in the electrolyte containing FEC, galvanostatic tests were performed. Electrodes were made from three samples of Si NPs: reference Si NPs exposed to the electrolyte but not irradiated as well as nanoparticles irradiated at 100 and $200 \mathrm{kGy}$ in presence of FEC. These three electrodes were used to fabricate test coin cells and cycled. The same current density was applied for the three samples (corresponding to a C/20 rate for the Si NPs exposed to the electrolyte containing FEC (Figure 8, black curve) and not irradiated). The first cycle charge and discharge potential vs. specific integrated current curves are displayed in Figure 8. Note that the first cycle lithiation capacity of the exposed sample is almost half of the theoretical specific capacity of Si. This is due to the fact that the active material is composed of silicon nanoparticles, having thus a high specific surface, and also to the amorphous nature of the sample which induces a higher capacity loss than crystalline nanoparticles. In general, with increasing irradiation dose, the specific capacity of the material decreases (Figure 8). Based on impedance measurements (Table 1 ), the $R_{c t}$ increase is the main consequence of irradiation in presence of FEC. We then can consider that the surface of the sample was modified in a way that finally reduces the possibility of lithium exchange with the active material. This also 
could be related to high amorphous-Si surface reactivity. Even if irreversibility is high for all samples, the quantity of electrons used for creating the SEI (the absolute irreversible capacity value) is lower for irradiated samples. For exposed samples, we use $450 \mathrm{mAh} \cdot \mathrm{g}^{-1}$ for passivation while for samples irradiated at $100 \mathrm{kGy}$, we only use $270 \mathrm{mAh} \cdot \mathrm{g}^{-1}$ and 174 $\mathrm{mAh} . \mathrm{g}^{-1}$ for the samples irradiated at $200 \mathrm{kGy}$. Moreover, if the first cycle coulombic efficiency (CE in \%) is lower, the stabilization of this CE is faster for irradiated samples (Figure S4 in Supporting Information). The exposed sample seems to take longer time to stabilize the consumption involved by the SEI while irradiated ones are more quickly passivated (Figure S4). The interphase created when the sample is irradiated appears to be stable and does require less electrons during the cycling for complete passivation.

As the capacity decrease was significant, the actual cycling rates applied were quite different between the samples. Furthermore the capacity decrease does not appear linked to an increase in polarization (see the $0.16 \mathrm{~V}$ plateau which appears for all samples). Therefore, we assume, in accordance with our EIS measurements showing that the charge transfer resistance is increased from $2 \Omega$ for the non-irradiated sample to $23 \Omega$ for the irradiated sample (Table 1 , last two columns), that the main issue remains with the kinetics (charge transfer), thus preventing the efficient transfer of $\mathrm{Li}^{+}$ions. This can also be put in line with our IR observations suggesting the formation of a cross-linked polymer in presence of the electrolyte containing FEC. Such a polymer would play a role in the inhibition of the $\mathrm{Li}^{+}$ions transfer. Indeed, if the SEI were insulating, then the resistance of SEI as measured by EIS experiments should be high, which is not observed here. Moreover, it would give rise to polarization through the increase of internal resistance, which is not observed here. Therefore the main issue of the SEI formed upon irradiation is related to the kinetics of charge transfer and not to insulating properties. The irradiation of the samples in the presence of FEC does not improve the performances of the materials, contrary to what we observed with carbon nanoparticles. ${ }^{23}$ Nevertheless, these nanoparticles were irradiated in an electrolyte without FEC. ${ }^{23}$ Actually, the Si-F bonds created appear to be detrimental for the electrochemical kinetics of silicon. In the case of Si NPs, the whole coverage of the nanoparticles was however achieved in presence of FEC. 


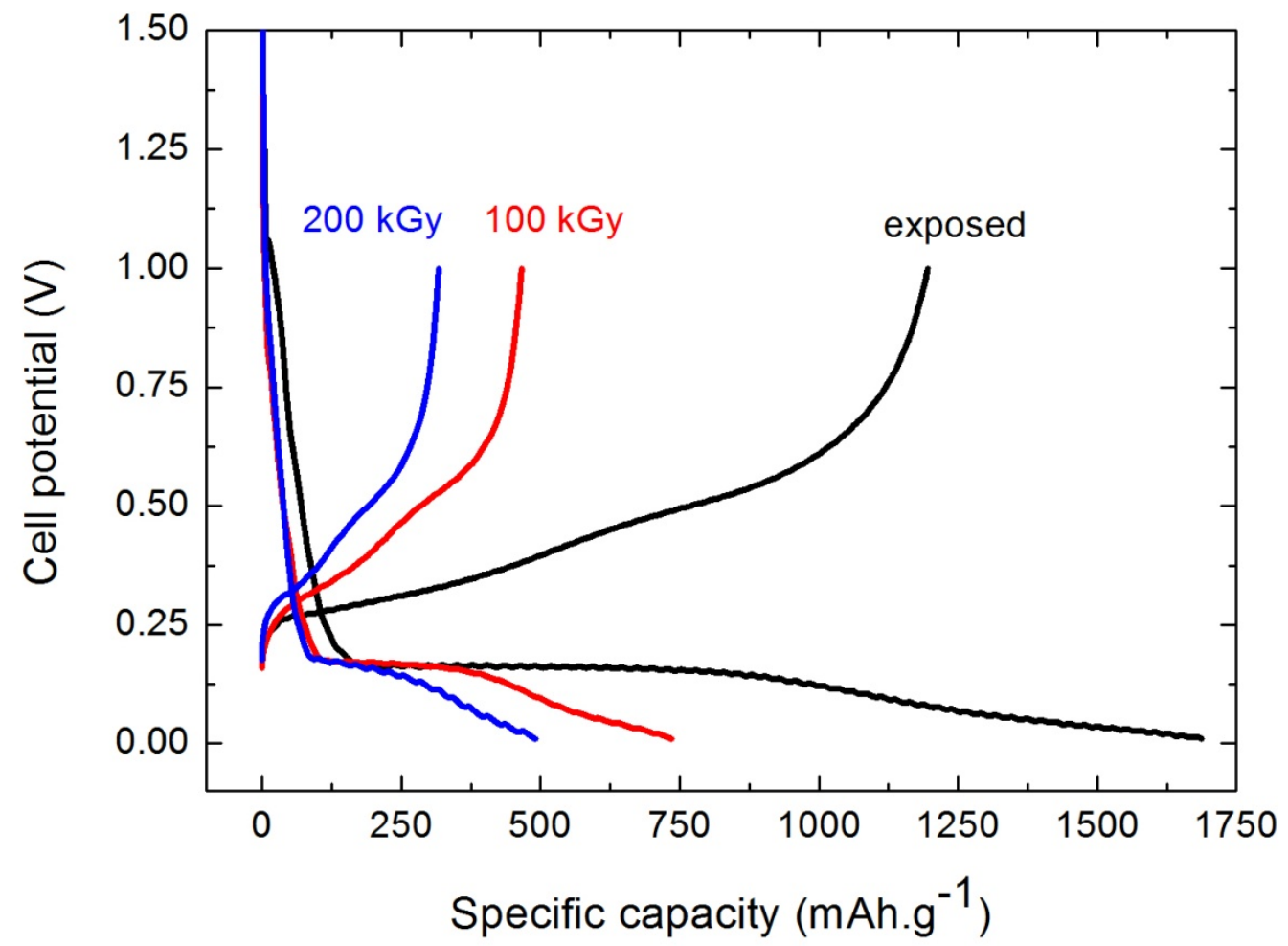

Figure 8. First cycle potential vs. specific capacity curve for the Si NPs exposed to the electrolyte containing FEC (black) and not irradiated; and after irradiation in the same electrolyte at a total dose of 100 kGy (red) and 200 kGy (blue).

\section{Conclusion}

Using irradiation, the formation of an artificial and homogeneous solid electrolyte interphase, having a thickness of a few nanometers, was achieved when the active material was irradiated in an electrolyte containing FEC, illustrating the role of this additive. For the FEC-free electrolyte and at the same irradiation dose, non-homogeneous carbon patches were found on the silicon surfaces. The products identified in the solid phase were shown to be consistent with those obtained during the cycling of Li-ion batteries $\left(\mathrm{Li}_{2} \mathrm{CO}_{3}, \mathrm{Li}_{\mathrm{x}} \mathrm{PF}_{\mathrm{y}} \mathrm{O}_{\mathrm{z}}\right.$ in the FEC-free electrolyte; $\mathrm{Li}_{2} \mathrm{CO}_{3}, \mathrm{LiF}, \mathrm{Li}_{x} \mathrm{PO}_{y}$ and $-\mathrm{Si}-\mathrm{F}$ bonds in the electrolyte containing FEC). Moreover, in both cases, a polymer was formed on the surface of the nanoparticles upon irradiation. The presence of FEC aids formation of a polymer which coats the whole surface of the nanoparticles when it is formed in sufficient amount. Galvanostatic experiments provide evidence that the specific capacity of the material irradiated in presence of FEC decreases when the irradiation dose increases. Electrochemical impedance spectroscopy 
experiments have shown that the main issue with this artificially-formed SEI is linked to kinetic limitation, as an efficient transfer of lithium ions is prevented. While the artificial SEI in this current work requires optimization for performance characteristics, the homogeneous and complete coverage suggests this method is promising for ex-situ SEI formation.

\section{Associated content}

\section{Supporting Information}

The Supporting Information is available free of charge on the ACS Publications website at DOI.

Figures S1-S4 are TEM images of Si NPs, EDX images of Si NPs irradiated at $200 \mathrm{kGy}$ in the electrolyte containing FEC, STEM images with EELS mapping and coulombic efficiency of the exposed and irradiated samples at C/20, respectively. Details on ion beam analysis are also provided.

\section{Acknowledgments}

The MOMENTOM (Initiative de Recherche Stratégique, Université Paris Saclay) project is gratefully acknowledged for financial support.

\section{References}

(1) Larcher, D.; Tarascon, J. M. Towards Greener and More Sustainable Batteries for Electrical Energy Storage. Nature Chem. 2015, 7, 19-29.

(2) Etacheri, V.; Marom, R.; Elazari, R.; Salitra, G.; Aurbach, D. Challenges in the Development of Advanced Li-Ion Batteries: A Review. Energy Environ. Sci. 2011, 4, 32433262.

(3) Tarascon, J. M.; Armand, M. Issues and Challenges Facing Rechargeable Lithium Batteries. Nature 2001, 414, 359-367.

(4) Campion, C. L.; Li, W. T.; Lucht, B. L. Thermal Decomposition of $\mathrm{LiPF}_{6}$ Based Electrolytes for Lithium-Ion Batteries. J. Electrochem. Soc. 2005, 152, A2327-A2334.

(5) $\mathrm{Xu}, \mathrm{K}$. Nonaqueous Liquid Electrolytes for Lithium-Based Rechargeable Batteries. Chem. Rev. 2004, 104, 4303-4417.

(6) Armand, M. T., J.-M. Building Better Batteries. Nature 2008, 451, 652-657.

(7) Wu, H.; Cui, Y. Designing Nanotructured Si Anodes for High Energy Lithium Ion Batteries. Nano Today 2012, 7, 414-429.

(8) Obrovac, M. N.; Christensen, L. Structural Changes in Silicon Anodes During Lithium Insertion/Extraction. Electrochem. Solid-State Lett. 2004, 7, A93-A96.

(9) Wang, A.; Kadam, S.; Li, H.; Shi, S.; Qi, Y. Review on Modeling of the Anode Solid Electrolyte Interphase (SEI) for Lithium-Ion Batteries. Computational Materials 2018, $4,15$.

(10) Kim, H.; Han, B.; Choo, J.; Cho, J. Three-Dimensional Porous Silicon Particles for Use in High-Performance Lithium Secondary Batteries. Angewandte Chem. Int. Ed. 2008, 47, 10151-10154. 
(11) Magasinski, A.; Dixon, P.; Hertzberg, B.; Kvit, A.; Ayala, J.; Yushin, G. HighPerformance Lithium-Ion Anodes Using a Hierarchical Bottom-up Approach. Nature Mat. 2010, 9, 353-358.

(12) Ge, M.; Fang, X.; Rong, J.; Zhou, C. Review of Porous Silicon Preparation and Its Application for Lithium-Ion Battery Anodes. Nanotechnology 2013, 24, 422001.

(13) Xu, W.; Vegunta, S. S. S.; Flake, J. C. Surface-Modified Silicon Nanowire Anodes for Lithium-Ion Batteries. J. Power Sources 2011, 196, 8583-8589.

(14) Zhang, S.; He, M.; Su, C.-C.; Zhang, Z. Advanced Electrolyte/Additive for Lithium-Ion Batteries with Silicon Anode. Current Opinion Chem. Engineer. 2016, 13, 24-35.

(15) Feng, K.; Li, M.; Liu, W.; Kashkooli, A. G.; Xiao, X.; Cai, M.; Chen, Z. Silicon-Based Anodes for Lithium-Ion Batteries: From Fundamentals to Practical Applications. Small 2018, 14, 1702737.

(16) Etacheri, V.; Haik, O.; Goffer, Y.; Roberts, G. A.; Stefan, I. C.; Fasching, R.; Aurbach, D. Effect of Fluoroethylene Carbonate (FEC) on the Performance and Surface Chemistry of Si-Nanowire Li-Ion Battery Anodes. Langmuir 2012, 28, 965-976.

(17) Nguyen, C. C.; Lucht, B. L. Comparative Study of Fluoroethylene Carbonate and Vinylene Carbonate for Silicon Anodes in Lithium Ion Batteries. J. Electrochem. Soc. 2014, 161, A-1933-A1938.

(18) Young, B. T.; Heskett, D. R.; Nguyen, C. C.; Nie, M.; Woicik, J. C.; Lucht, B. L. Hard X-Ray Photoelectron Spectroscopy (HAXPES) Investigation of the Silicon Solid Electrolyte Interphase (SEI) in Lithium-Ion Batteries. ACS Appl. Mater. Interfaces 2015, 7, 20004-20011.

(19) Ortiz, D.; Steinmetz, V.; Durand, D.; Legand, S.; Dauvois, V.; Maître, P.; Le Caër, S. Radiolysis as a Solution for Accelerated Ageing Studies of Electrolytes in LithiumIon Batteries. Nature Comm. 2015, 6, 6950.

(20) Ortiz, D.; Jimenez Gordon, I.; Baltaze, J.-P.; Hernandez-Alba, O.; Legand, S.; Dauvois, V.; Si Larbi, G.; Schmidhammer, U.; Marignier, J. L.; Martin, J.-F. et al. Electrolytes Ageing in Lithium-Ion Batteries: A Mechanistic Study from Picosecond to Long Timescales. ChemSusChem 2015, 8, 3605-3616.

(21) Ortiz, D.; Jimenez Gordon, I.; Legand, S.; Dauvois, V.; Baltaze, J.-P.; Marignier, J. L.; Martin, J.-F.; Belloni, J.; Mostafavi, M.; Le Caër, S. Role of $\mathrm{PF}_{6}{ }^{-}$in the Radiolytical and Electrochemical Degradation of Propylene Carbonate Solutions. J. Power Sources 2016, 326.

(22) Wang, F.; Varenne, F.; Ortiz, D.; Pinzio, V.; Mostafavi, M.; Le Caër, S. Degradation of an Ethylene Carbonate/Diethyl Carbonate Mixture by Using Ionizing Radiation. ChemPhysChem 2017, 18, 2799-2806.

(23) Varenne, F.; Alper, J. P.; Miserque, F.; Bongu, C. S.; Boulineau, A.; Martin, J.F.; Dauvois, V.; Demarque, A.; Bouhier, M.; Boismain, F. et al. Ex Situ Solid Electrolyte Interphase Synthesis Via Radiolysis of Li-Ion Battery Anode-Electrolyte System for Improved Coulombic Efficiency. Sustainable Energy Fuels 2018, 2, 2100-2108.

(24) Sourice, J.; Quinsac, A.; Leconte, Y.; Sublemontier, O.; Porcher, W.; Haon, C.; Bordes, A.; De Vito, E.; Boulineau, A.; Si Larbi, S. et al. One-Step Synthesis of Si@C Nanoparticles by Laser Pyrolysis: High-Capacity Anode Material for Lithium-Ion Batteries. ACS Appl. Mater. Interfaces 2015, 7, 6637-6644.

(25) Sourice, J.; Bordes, A.; Boulineau, A.; Alper, J. P.; Franger, S.; Quinsac, A.; Habert, A.; Leconte, Y.; De Vito, E.; Porcher, W. et al. Core-Shell Amorphous SiliconCarbon Nanoparticles for High Performance Anodes in Lithium Ion Batteries. J. Power Sources 2016, 328, 527-535.

(26) Fricke, H.; Hart, E. J. In Radiation Dosimetry; Second Edition ed.; Attix, F. H., Roesch, W. C., Eds.; Academic press: New York and London, 1966; Vol. 2, p 167-232. 
(27) Khodja, H.; Berthoumieux, E.; Daudin, L.; Gallien, J. P. The Pierre Süe Laboratory Nuclear Microprobe as a Multi-Disciplinary Analysis Tool. Nucl. Instr. Meth. Phys. Res. B 2001, 181, 83-86.

(28) Choi, N.-S.; Han Yew, K.; Youl Lee, K.; Sung, M.; Kim, H.; Kim, S.-S. Effect of Fluoroethylene Carbonate Additive on Interfacial Properties of Silicon Thin-Film Electrode. J. Power Sources 2006, 161, 1254-1259.

(29) Fortunato, B.; Mirone, P.; Fini, G. Infrared and Raman Spectra and Vibrational Assignment of Ethylene Carbonate. Spectrochim. Acta 1971, 27A, 1917-1927.

(30) Yohannes, Y. B.; Lin, S. D.; Wu, N.-L. In Situ Drifts Analysis of Solid Electrolyte Interphase of Si-Based Anode with and without Fluoroethylene Carbonate Additive. J. Electrochem. Soc. 2017, 164, A3641-A3648.

(31) Saqib, N.; Ganim, C. M.; Shelton, A. E.; Porter, J. M. On the Decomposition of Carbonate-Based Lithium-Ion Battery Electrolytes Studied Using Operando Infrared Spectroscopy. J. Electrochem. Soc. 2018, 165, A4051-A4057.

(32) Masia, M.; Probst, M.; Rey, R. Ethylene Carbonate- $-\mathrm{Li}^{+}$: A Theoretical Study of Structural and Vibrational Properties in Gas and Liquid Phases. J. Phys. Chem. B 2004, 108, 2016-2027.

(33) Chai, J.; Liu, Z.; Ma, J.; Wang, J.; Liu, X.; Liu, H.; Zhang, J.; Cui, G.; Chen, L. In Situ Generation of Poly (Vinylene Carbonate) Based Solid Electrolyte with Interfacial Stability for $\mathrm{LiCoO}_{2}$ Lithium Batteries. Adv. Science 2017, 4, 1600377.

(34) Shkrob, I. A.; Zhu, Y.; Marin, T. W.; Abraham, D. Reduction of Carbonate Electrolytes and the Formation of Solid-Electrolyte Interface (SEI) in Lithium-Ion Batteries. 2. Radiolytically Induced Polymerization of Ethylene Carbonate. J. Phys. Chem. C 2013, 117, 19270-19279.

(35) Michan, A. L.; Parimalan, B. S.; Leskes, M.; Kerber, R. N.; Yoon, T.; Grey, C. P.; Lucht, B. L. Fluoroethylene Carbonate and Vinylene Carbonate Reduction: Understanding Lithium-Ion Battery Electrolyte Additives and Solid Electrolyte Interphase Formation. Chem. Mater. 2016, 28, 8149-8159.

(36) Gireaud, L.; Grugeon, S.; Laruelle, S.; Pilard, S.; Tarascon, J. M. Identification of Li Battery Electrolyte Degradation Products through Direct Synthesis and Characterization of Alkyl Carbonate Salts. J. Electrochem. Soc. 2005, 152, A850-A857.

(37) Pucic, I.; Jurkin, T. Ftir Assessment of Poly(Ethylene Oxide) Irradiated in Solid State, Melt and Aqueous Solution. Rad. Phys. Chem. 2012, 81, 1426-1429.

(38) Alves Dalla Corte, D.; Caillon, G.; Jordy, C.; Chazalviel, J.-N.; Rosso, M.; Ozanam, F. Spectroscopic Insight into Li-Ion Batteries During Operation: An Alternative Infrared Approach. Adv. Energy Mater. 2016, 6, 1501768.

(39) Shkrob, I. A.; Wishart, J. F.; Abraham, D. P. What Makes Fluoroethylene Carbonate Different? . J. Phys. Chem. C 2015, 119, 14954-14964.

(40) Yoon, D.-H.; Marinaro, M.; Axmann, P.; Wohlfahrt-Mehrens, M. Quantitative Analysis of Consumption of Fluoroethylene Carbonate Additives on Silicon Alloy Anodes. $J$. Electrochem. Soc. 2018, 165, A2467-A2469.

(41) Brooker, M. H.; Wang, J. Raman and Infrared Studies of Lithium and Cesium Carbonates. Spectrochimica Acta 1992, 48A, 999-1008.

(42) Nguyen, C. C.; Lucht, B. L. Comparative Study of Fluoroethylene Carbonate and Vinylene Carbonate for Silicon Anodes in Lithium Ion Batteries. J. Electrochem. Soc. 2014, 161, A1933-A1938.

(43) An, S. J.; Li, J.; Daniel, C.; Mohanty, D.; Nagpure, S.; Wood III, D. L. The State of Understanding of the Lithium-Ion-Battery Graphite Solid Electrolyte Interphase (SEI) and Its Relationship to Formation Cycling. Carbon 2016, 105, 52-76. 
(44) Marom, R.; Haik, O.; Aurbach, D.; Halalay, I. C. Revisiting $\mathrm{LiClO}_{4}$ as an Electrolyte for Rechargeable Lithium-Ion Batteries. J. Electrochem. Soc. 2010, 157, A972A983.

(45) Leifer, N.; Smart, M. C.; Prakash, G. K. S.; Gonzalez, L.; Sanchez, L.; Smith, K. A.; Bhalla, P.; Grey, C. P.; Greenbaum, S. G. ${ }^{13}$ C Solid State NMR Suggests Unusual Breakdown Products in SEI Formation on Lithium Ion Electrodes. J. Electrochem. Soc. 2011, 158, A471-A480.

(46) Jin, Y.; Kneusels, N.-J. H.; Marbella, L. E.; Castillo-Martinez, E.; Magusin, P. C. M.; Weatherup, R. S.; Jonsson, E.; Liu, T.; Paul, S.; Grey, C. P. Understanding Fluoroethylene Carbonate and Vinylene Carbonate Based Electrolytes for Si Anodes in Lithium Ion Batteries with NMR Spectroscopy. J. Am. Chem. Soc. 2018, 140, 9854-9867.

(47) Yoon, T.; Milien, M. S.; Parimalam, B. S.; Lucht, B. L. Thermal Decomposition of the Solid Electrolyte Interphase (SEI) on Silicon Electrodes for Lithium Ion Batteries. Chem. Mater. 2017, 29, 3237-3245. 
TOC Graphic

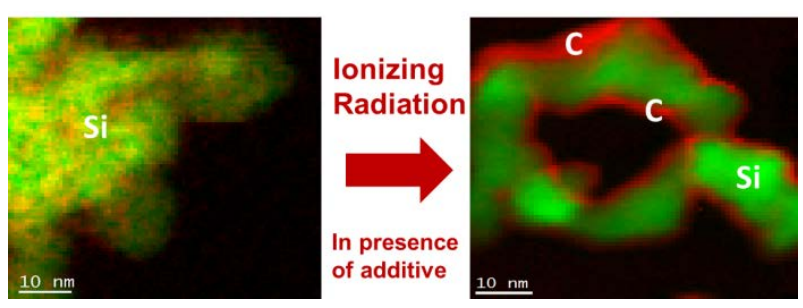

